\title{
Virus Particles of Cucumber Green Mottle Mosaic Tobamovirus Move Systemically in the Phloem of Infected Cucumber Plants
}

\author{
Laureano Simón-Buela and Fernando García-Arenal \\ Dpto. Biotecnología, ETSI Agrónomos, Universidad Politécnica de Madrid, 28040 Madrid, Spain \\ Accepted 20 October 1998.
}

Systemic movement through the phloem of infected host plants is a key process in the life cycle of plant viruses, knowledge of which is scant. A main point to be elucidated is the structural form in which virus infection moves within the phloem. Indirect evidence suggests that virions might be the viral structure that moves in the phloem, but data from direct analysis in phloem sap have not been reported. We have done such analysis in the system cucumber (from which phloem exudate can be collected) / cucumber green mottle mosaic tobamovirus (CGMMV). CGMMV has structurally well-characterized particles. Both CGMMV coat protein and RNA were found in phloem exudate from infected cucumbers. Analysis of the accessibility of CGMMV RNA in phloem exudate to RNase A indicates that it is protected within a ribonucleoprotein structure. The accessibility to RNase A of the RNA in these structures was as in virus particles. Centrifugation analyses showed that the ribonucleoprotein structures in the phloem exudate have the same mass and isopycnic density as virions. Virus particles indistinguishable from purified virions were detected by electron microscopy in phloem exudate. No evidence of free RNA or other CGMMV-related structure was found in phloem exudate of infected plants. These results indicate that CGMMV movement in the phloem occurs mainly, if not exclusively, in the form of virus particles.

Additional keywords: phloem transport, systemic infection, virus movement.

Viruses are pathogens that systemically infect susceptible plant hosts. For those viruses that are not limited to the vascular tissues, infection starts with the initial replication in a few cells, and follows with the colonization of the plant, a process that consists of two different steps. The first step is cell-to-cell movement via the plasmodesmata from the initially infected cell(s), through parenchymatic tissues, to reach the vasculature. The second step is long-distance movement through the vascular tissues. Cell-to-cell movement between mesophyll cells has been extensively studied during the past 10 years, leading to some understanding of the virus factors involved (Carrington et al. 1996). The major virus factors in-

Corresponding author: Fernando García-Arenal; Telephone: 34-913365768; Fax: 34-91-3365757; E-mail: fga@ bit.etsia.upm.es volved in cell-to-cell movement are the movement proteins (MPs), virus-encoded proteins that target the plasmodesmata and modify the size exclusion limit of the plasmodesmal pore (Tomenius et al. 1987; Wolf et al. 1989). Much less is known about long-distance movement. For most systems studied, evidence indicates that movement occurs via the phloem, and it follows the path of photoassimilate transport (Leisner and Turgeon 1993). Also, for many RNA viruses in those host plants analyzed, MPs are not sufficient for long-distance movement to occur, and a functional coat protein (CP) is also usually required (e.g., Dawson et al. 1988; Allison et al. 1990; Hacker et al. 1992; Dolja et al. 1994). Information is scarcer as to how viruses access the vasculature, enter the sieve elements (SE), move long distance, and exit the phloem to reinfect parenchymatic tissues. Also, little is known about the host factors that interact with viral proteins and nucleic acids, though evidence indicates that they are different from those involved in cell-to-cell movement (for recent reviews see Carrington et al. 1996; Gilbertson and Lucas 1996; Nelson and van Bel 1998).

A central point in understanding virus movement in the phloem is to determine the form in which viruses move. This information is essential to understand how viruses interact with host factors during entry into, transit through, and exit from the sieve tubes (Nelson and van Bel 1998). For a number of viruses it has been suggested that movement in the phloem involves virions. The strongest evidence comes from tobacco mosaic tobamovirus (TMV), for which a functional $\mathrm{CP}$ and a functional origin of assembly are needed for systemic movement to occur (Oxelfelt 1975; Saito et al. 1990; Ding et al. 1996). Also, virus particles have been observed by electron microscopy in SE of TMV-infected plants (Esau and Cronshaw 1967). On the other hand, it has been proposed that the $\mathrm{CP}$ could also interact with the genomic RNA to form a different ribonucleoprotein complex, the so-called informosome (Dorokhov et al. 1983). Direct evidence for the form in which viruses, including TMV, move in SE is lacking, hindered by technical difficulties.

A main experimental drawback with most host plants is the difficulty in obtaining samples of phloem sap. We have circumvented this problem by analyzing the form in which phloem movement occurs in cucumber plants infected with cucumber green mottle mosaic tobamovirus (CGMMV). CGMMV has a genome organization homologous to that of TMV (Ugaki et al. 1991), and its virions have structural properties very simi- 
lar to those, well-characterized, of TMV (Altschuh et al. 1987). Cucumber is a member of the family Cucurbitaceae, from which phloem sap can be obtained in reasonable amounts as an exudate from sectioned internodes (Read and Northcote 1983). Our results support the hypothesis that CGMMV moves within the phloem in the form of virus particles.

\section{RESULTS}

\section{CGMMV CP and RNA are present in phloem exudate of infected cucumber plants.}

CGMMV was inoculated to the cotyledons of young cucumber plants about 10 days after sowing, when the first true leaf was expanding and had a length of 1.5 to $2 \mathrm{~cm}$ at its main vein. No symptoms were observed in the inoculated cotyledons, and systemic symptoms were first detected at about 12 days post inoculation (dpi) in the expanding fifth leaf.

Figure 1A shows the patterns of proteins in phloem exudate, and in extracts collected from the fifth internode or from the expanding fifth true leaf, of a CGMMV-infected cucumber plant $12 \mathrm{dpi}$. The protein pattern in the phloem exudate was as reported in the literature (Read and Northcote 1983; Fig. 1A, lane 2). The pattern of proteins clearly differed between the phloem exudate and the leaf (Fig. 1A, lane 1) and, more importantly, between the phloem exudate and internode extracts (Fig. 1A, lane 3), indicating little contamination of the phloem exudate with sap from parenchyma cells of the internode. When a duplicate gel was transferred to nitrocellulose and probed with an antiserum against wheat rubisco, both the large and small subunits of rubisco were detected in the leaf and internode extracts (Fig. 1B, lanes 1 and 3), but not in the phloem exudate (Fig. 1B, lane 2). This, again, indicates the absence of contamination of phloem exudate with cytoplasm from stem parenchyma cells. When a similar immunoblot was probed with an antiserum against CGMMV, the $\mathrm{CP}$ was detected in extracts of leaf and internode (Fig. 1C, lanes 1 and 3 ), as well as in the phloem exudate (Fig. 1C, lane 2). For the
CGMMV CP antiserum, the densitometric absorbance of the immunodetected band varied linearly with the logarithm of the amount of CP between $50 \mathrm{ng}$ and $1 \mu \mathrm{g}$ (not shown). Because the detection limit was $50 \mathrm{ng}$, CGMMV CP could not be detected in phloem exudate at early times post inoculation. At 12 dpi, measurements from different experiments (not shown) indicated about $50 \mathrm{ng}$ of CGMMV CP per $\mu$ of phloem exudate.

When phloem exudate was used to inoculate the cotyledons of young cucumber plants, four out of four inoculated plants became infected, indicating the presence of infectious form(s) of CGMMV RNA. The infectivity of the phloem exudate, measured in a local lesion host (Chenopodium amaranticolor Coste \& Reyn.) was similar to that of purified virions (data not shown). RT-PCR (reverse transcription-polymerase chain reaction) products generated with primers LS1 and LS2 (nucleotides 4321 to 4680) were detected in phenol-extracted phloem exudates as early as $3 \mathrm{dpi}$ (Fig. 2A, lane 1), and the amount of cDNA synthesized from samples taken every 3 days increased steadily until 12 dpi (Fig. 2A, lanes 6 and 7), when the sensitivity of the assay was saturated. Under the RTPCR conditions used, the densitometric absorbance of the cDNA band varied linearly with the logarithm of the RNA amount from $10 \mathrm{pg}$ (lower detection limit) to $1 \mu \mathrm{g}$ (Fig. 2B and $\mathrm{C}$ ). Thus, the amount of CGMMV RNA in the internode beneath the youngest developing leaf, from where samples were taken, increased steadily as infection progressed and the number of exporting leaves increased. For subsequent experiments samples were always taken at 9 to $12 \mathrm{dpi}$.

When the phloem exudate was not phenol extracted, no CGMMV RNA was detected by RT-PCR analysis (Fig. 2D, lane 1 vs lane 2). If purified CGMMV RNA was mixed with phloem exudate from a noninoculated plant, the sequence from nucleotides 4321 to 4680 was efficiently amplified by RT-PCR (Fig. 2D, lane 3). Thus, the proteins in the phloem exudate that are eliminated by phenol extraction do not have an inhibitory role in the RT or PCR. Rather, the results in Figure $2 \mathrm{C}$ indicate that CGMMV RNA in the phloem exudate is

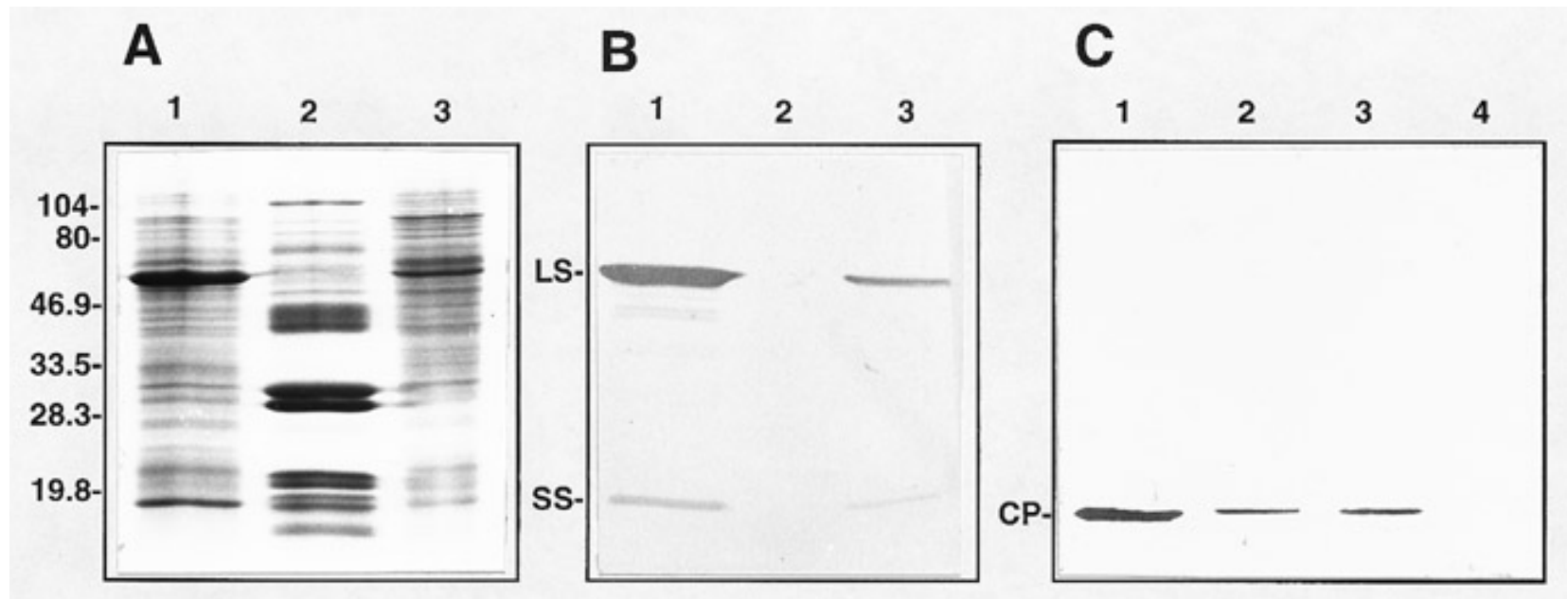

Fig. 1. Protein analysis in phloem exudate and in extracts of either an internode or leaf of cucumber green mottle mosaic tobamovirus (CGMMV)infected cucumber plants. Ten micrograms of total protein from a leaf extract (lanes 1), phloem exudate (lanes 2), and internode extract (lanes 3 ), from CGMMV-infected plants 12 days post inoculation (dpi) were electrophoresed in 15\% sodium dodecyl sulfate-polyacrylamide gels, and either (A) stained with Coomassie Brilliant Blue or transferred to nitrocellulose and probed with antisera raised against (B) rubisco or (C) CGMMV. The mobility of molecular mass markers is shown ( $\mathrm{kDa}$ ) at the left of $\mathbf{A}$. The mobility of rubisco large and small subunits (LS and SS) and of CGMMV-CP (CP) is indicated at the left of $\mathbf{B}$ and $\mathbf{C}$, respectively. Lane 4 in $\mathbf{C}$ corresponds to a leaf extract of a noninoculated cucumber plant. 
in the form of a ribonucleoprotein structure, possibly involving CGMMV CP.

\section{Characterization of the viral structure(s) present in the phloem exudate of CGMMV-infected cucumber plants.}

To characterize the viral structure(s) present in the phloem exudate of CGMMV-infected cucumber plants, different approaches were followed. The well-characterized CP-RNA structure of purified virions was used as a reference.

As a first approach, the degree of protection of the viral RNA against digestion by RNase A was analyzed. Samples of

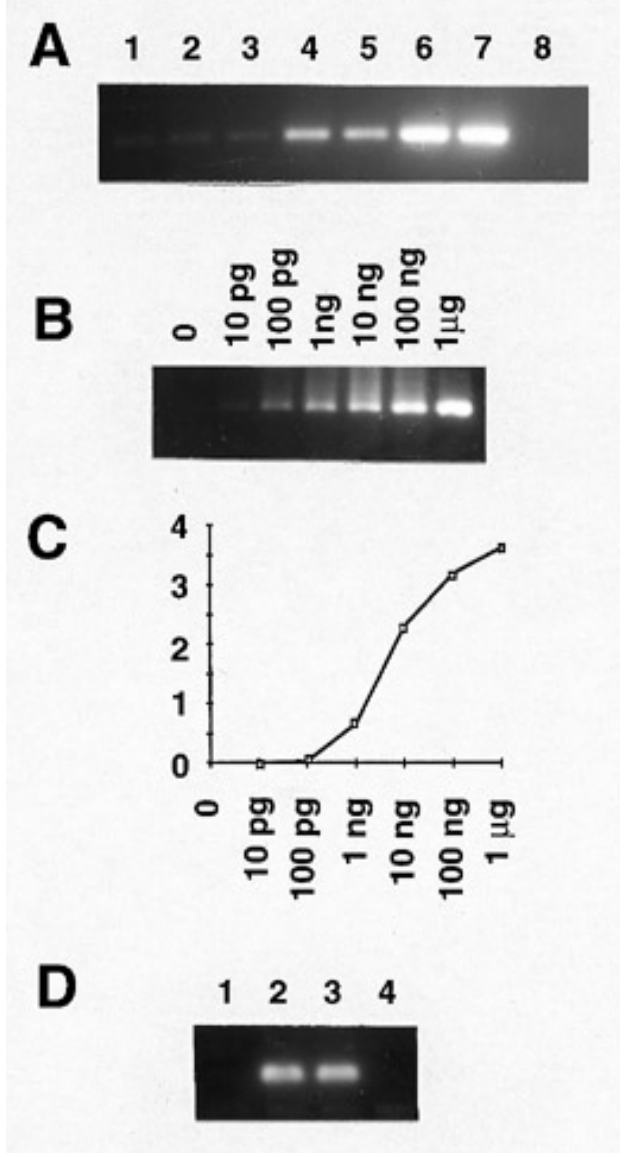

Fig. 2. RT-PCR (reverse transcription-polymerase chain reaction) detection of cucumber green mottle mosaic tobamovirus (CGMMV) RNA in the phloem exudate of CGMMV-infected cucumber plants. A, Time course of CGMMV RNA (nucleotides 4321 to 4680) detection. RT-PCR was done on phloem exudate collected from the second internode at 3 days post inoculation (dpi; lane 1), at 6 dpi from the second (lane 2) and third (lane 3) internodes, at $9 \mathrm{dpi}$ from the third (lane 4) and fourth (lane 5) internodes, and at $12 \mathrm{dpi}$ from the fourth (lane 6) and fifth (lane 7) internodes. Lane 8 shows RT-PCR done on phloem exudate collected from the fifth internode of mock-inoculated plants at 12 dpi. B, RT-PCR products (nucleotides 4321 to 4680) obtained from different amounts of CGMMV RNA. C, A graph of the relationship between densitometric quantification of RT-PCR products (B) and the amount of CGMMV RNA. Numbers on the $y$ axis are in arbitrary units. D, RT-PCR detection of CGMMV RNA (nucleotides 4321 to 4680) was done on phloem exudate from CGMMV-inoculated cucumber plants without (lane 1) or with (lane 2) a previous phenol extraction, and on phloem exudate to which $7.5 \mathrm{ng}$ of CGMMV RNA (lane 3) or $25 \mu \mathrm{l}$ of phloem exudate buffer (lane 4) was added previously to RT-PCR. A, B, and D, Agarose gels, stained with ethidium bromide, of electrophoresis of RT-PCR products. phloem exudate from CGMMV-infected cucumber plants, or of purified virions mixed with phloem exudate from noninoculated plants, were incubated for $1 \mathrm{~h}$ at $37^{\circ} \mathrm{C}$ with different concentrations of RNase A and phenol extracted; then the region between nucleotides 4321 and 4680 was amplified by RT-PCR. Figure $3 \mathrm{~A}$ and $\mathrm{B}$ show that CGMMV RNA in phloem exudate of infected plants, or in purified virions mixed with phloem exudate of noninoculated plants, was similarly protected against a concentration up to $12.5 \mathrm{mg}$ of RNase A per $\mathrm{ml}$. The degree of protection against RNase A of different regions of CGMMV genomic RNA in the phloem exudate of infected plants was also analyzed. For this, phloem exudate was treated with $0.05 \mathrm{mg}$ of RNase A per ml, cDNA was synthesized by reverse transcription with a primer complementary to the $3^{\prime}$ end of CGMMV RNA, and different genomic regions were PCR amplified. Figure 4 shows that the level of amplification was lower the more $5^{\prime}$ proximal the region to be amplified: it was lowest for the sequence limited by nucleotides 179 and 824, intermediate for nucleotides 756 to 1381, and highest for nucleotides 4321 to 4680 . To demonstrate that these differences in RT-PCR amplification efficiency were not due to a lower efficiency of cDNA synthesis along the 6,700 nucleotide-long CGMMV RNA, cDNA was also synthesized with the reverse primers used for PCR, with results similar to those in Figure 4 (not shown). Figure 4 also shows that the differential protection of the various genomic regions occurred as well in CGMMV virion RNA when purified virions, mixed with phloem exudate of noninoculated plants prior to RNase digestion, were assayed. Thus, the degree of protection against RNase A of the RNA in the CGMMV-related structure in the phloem exudate of infected plants varied according to the region; protection was least toward the $5^{\prime}$ end, as was also the case with virions. That a cDNA synthesized with a primer complementary to the $3^{\prime}$ end did allow PCR amplification of sequences near its $5^{\prime}$ end shows that there were no discontinuities in the protection of the RNA against RNase A.

A second approach to characterize the CGMMV-related structure in the phloem of infected cucumber plants was to compare their mass and isopycnic density with those of purified virions. For this, either phloem exudates of CGMMV-

\section{$\begin{array}{llllllllll}1 & 2 & 3 & 4 & 5 & 6 & 7 & 8 & 9 & 10\end{array}$}

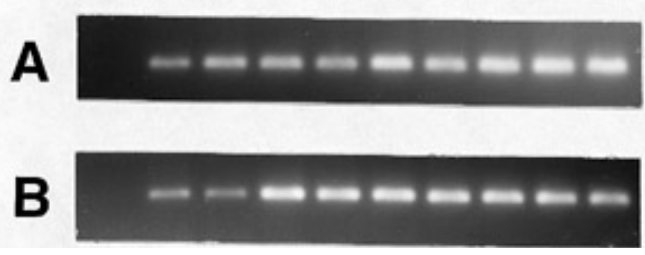

Fig. 3. Protection of cucumber green mottle mosaic tobamovirus (CGMMV) RNA against RNase A. Five microliters of phloem exudate collected 12 days post inoculation (dpi) from CGMMV-infected cucumbers, plus (A) $20 \mu$ of phloem exudation buffer (PEB) or (B) $125 \mathrm{ng}$ of CGMMV virions plus $5 \mu \mathrm{l}$ of phloem exudate of noninoculated cucumber plants plus $20 \mu \mathrm{l}$ of PEB was digested with 25 (lane 1), 12.5 (lane 2), 5 (lane 3), $5 \times 10^{-1}$ (lane 4), $5 \times 10^{-2}$ (lane 5), $5 \times 10^{-3}$ (lane 6), $5 \times 10^{-4}$ (lane 7), $5 \times 10^{-5}$ (lane 8), $5 \times 10^{-6}$ (lane 9), and $0 \mathrm{mg} / \mathrm{ml}$ (lane 10), (final concentration) of RNase A at $37^{\circ} \mathrm{C}$ for $1 \mathrm{~h}$, and phenol extracted, and the nondigested RNA (nucleotides 4321 to 4680) was detected by RT-PCR (reverse transcription-polymerase chain reaction) amplification and agarose gel electrophoresis. 
infected cucumbers, or purified virions, alone or mixed with phloem exudate from noninoculated cucumbers, were centrifuged in 10 to $30 \%$ sucrose gradients or in discontinuous $\mathrm{CsCl}$ gradients. After centrifugation, $0.5-\mathrm{ml}$ fractions were collected by hand, and the presence of CGMMV RNA in those fractions was detected by RT-PCR amplification of the 4321 to 4680 nucleotide region. CGMMV RNA was detected in the same fractions of sucrose (Fig. 5A), or $\mathrm{CsCl}$ (Fig. 5B), gradients (fractions 8 to 14 for sucrose gradients, and fractions 6 to 9 for $\mathrm{CsCl}$ ones) loaded with phloem exudate of infected plants or with purified virions, either alone (not shown) or mixed with phloem exudate of noninoculated plants. Densitometric analyses of the intensities of the amplified bands showed that the sedimentation profiles were similar both for virions in phloem exudate of infected plants and for purified virions. These results indicate that the CGMMV structure in cucumber phloem exudate has the same mass and isopycnic density as purified virions. Moreover, these results indicate that no other CGMMV RNA-containing structure was present in phloem exudate of infected plants in detectable amounts.

All fractions from the sucrose gradients in which CGMMV RNA was detected were observed under the electron microscope after immunocapture on grids coated with antiserum raised against CGMMV, and negative staining. Rigid rods, $300 \mathrm{~nm}$ in length and $20 \mathrm{~nm}$ in diameter, were observed in all RT-PCR positive fractions, albeit in different amounts, regardless of whether they were either from gradient fractions of phloem exudate of infected plants or from purified virions mixed with phloem exudate of noninoculated cucumbers (Fig. $6 \mathrm{~A}$ and $\mathrm{B})$.

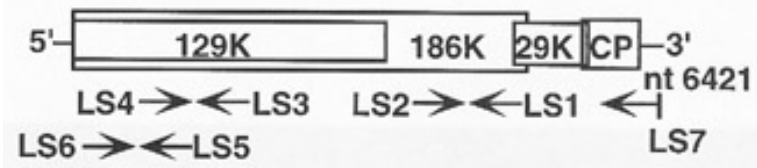

$\begin{array}{llll}1 & 2 & 3 & 4\end{array}$

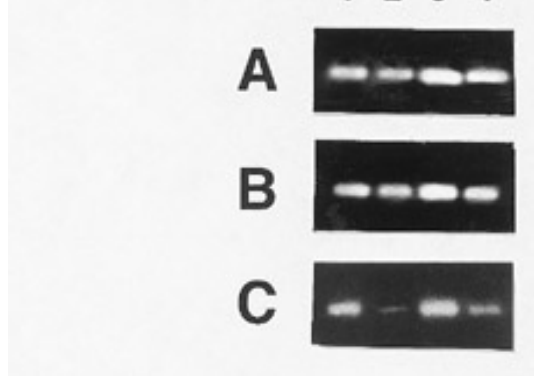

Fig. 4. Protection against RNase $A$ of different regions of cucumber green mottle mosaic tobamovirus (CGMMV) RNA. Purified virions (125 ng) suspended in phloem exudation buffer (PEB) mixed with phloem exudate from noninoculated cucumber plants (lanes 1 and 2), or phloem exudate from CGMMV-infected plants (lanes 3 and 4), were incubated $\left(1 \mathrm{~h}, 37^{\circ} \mathrm{C}\right)$ without (lanes 1 and 3) or with (lanes 2 and 4$) 5 \times$ $10^{-2} \mathrm{mg}$ of RNase A per ml and phenol extracted, and a cDNA was synthesized by RT (reverse transcription) from the RNA 3' end (primer LS7). PCR (polymerase chain reaction) was done on this cDNA to amplify the regions limited by nucleotides 4321 to 4680 (primers LS1 and LS2; A), 765 to 1381 (primers LS3 and LS4; B), or 178 to 824 (primers LS5 and LS6; C). PCR products were analyzed by agarose gel electrophoresis. Genetic structure of CGMMV RNA and positions of the primers used are also shown.
Thus, the results presented in this section indicate that CGMMV particles were found in phloem exudate of CGMMV-infected cucumber plants, and that no other CGMMV-related structure was detected.

\section{DISCUSSION}

Long-distance movement through the phloem of the host plant is a key process in the life cycle of plant viruses. If viral infection remains limited to the inoculated leaves, plants are functionally resistant under natural conditions, as they show no symptoms and are poor sources for virus spread to other host plants. Knowledge of long-distance movement mechanisms is scant, and much remains to be elucidated about how viruses enter the mature, functional SE, move to distant sink organs with the phloem translocation stream, and exit the phloem to re-infect parenchymatic tissues. In particular, there is the question of the structural form in which viral nucleic acids are translocated within the phloem. A widely accepted hypothesis considers that the moving structure is the virus particle. This hypothesis rests on indirect, inconclusive evidence derived in large part from the study of TMV, possibly the most-studied virus regarding movement functions. Virions, as aggregates or scattered particles, have been observed at the electron microscope in mature SE of TMV-infected plants (Esau and Cronshaw 1967). Whether they represent active movement structures or virus accumulation at late infection times is unclear, since aggregates of virus particles were also observed in all other examined tissues, including mature tracheary elements. It has been accepted since early experiments in the 1930s (Caldwell 1934) that TMV does not move through the xylem. A second line of evidence derives from the fact that many RNA viruses in the analyzed host plants require the CP for systemic infection, including those viruses that do not need the CP for cell-to-cell movement (reviewed in Nelson and van Bel 1998). TMV does not require the CP for cellto-cell movement, but a functional $\mathrm{CP}$, as well as a functional origin of assembly, is needed for phloem-dependent accumulation (Oxelfelt 1975; Dawson et al. 1988; Saito et al. 1990; Ding et al. 1996). Analysis of the process of infection by CPdeficient mutants indicates that these may reach the phloem parenchyma cells of minor veins (Ding et al. 1996). This might suggest that the $\mathrm{CP}$ is necessary only after the infection has traversed the bundle sheath/phloem interface. All these data suggest that virions could be necessary for phloem transport. Alternatively, it has been proposed that the CP could interact with the viral RNA to form not a virion but an informosome-like structure, which would be transported in the phloem (Dorokhov et al. 1983). Evidence that virion formation is required for systemic infection also derives from analyses of other systems, for instance, red clover necrotic mosaic dianthovirus (Vaewhongs and Lommel 1995). For potato virus X potexvirus, the $\mathrm{CP}$ has been shown to move in the phloem, though no evidence for the infectious moving structure has been presented (Santa Cruz et al. 1998). For cucumber mosaic cucumovirus (CMV) RNA (Wintermantel et al. 1997), CP and virions were detected in mature SE (Blackman et al. 1998). Virions in the phloem were viewed as membrane-limited aggregates, and their role in movement is not clear. Thus, even for the best-characterized systems, no direct evidence has been reported for a role of virus particles in long-distance 
movement. A reason for this lack of direct evidence may be the difficulty in obtaining phloem sap from most experimental host plants.

To obtain this direct evidence we have analyzed the viral structure(s) present in phloem sap. We have used cucumber plants, since phloem exudate can be collected in reasonable amounts from sectioned petioles or internodes (Schulz 1998). As infecting virus we have used CGMMV, a cucurbitinfecting tobamovirus that shares with TMV the genetic, as well as the particle, structure (Altschuh et al. 1987; Ugaki et al 1991). We have shown that phloem exudate of CGMMVinfected cucumbers was infectious and that, within the limits of the assay methods employed, free viral RNA was not detected in phloem exudate. Viral RNA appears to be mostly in a ribonucleoprotein structure. Protection of viral RNA against RNAse $\mathrm{A}$ in the structures present in phloem exudate paralleled that of virion RNA, when purified virus particles were mixed with phloem exudate of noninoculated cucumbers. It was weaker on the $5^{\prime}$ proximal part of the RNA that corresponds to a region of the virion rod in which the affinity of $\mathrm{CP}$ for RNA is less than in the central two-thirds of the particle (Perham and Wilson 1978; Wilson et al. 1981). We have also shown that virions were present in phloem exudate, and that the main viral structure in phloem exudate had the same mass and density as purified virus particles. It should be stressed that no evidence of ribonucleoprotein structures with the properties described by Dorokhov et al. (1984) was found.
These structures were reported to have a higher isopycnic density than virions, and their RNAs showed less resistance against RNase A (Dorokhov et al. 1983, 1984). Thus, virions appear to be the main structure for GCMMV movement in the $\mathrm{SE}$, although the presence of minor amounts of other, undetected structures cannot be ruled out.

Our results pose the question, how do CGMMV virions access the SE? There is evidence that plasmodesmata between companion cells, or intermediary cells, and SE, interact differently with viral components than those connecting other cell types, and have larger size exclusion limits, compatible with the passage of intact virus particles (Kempers et al. 1993; Kempers and van Bel 1997; Santa-Cruz et al. 1998). Alternatively, viral CP and RNA, synthesized in the companion, or intermediary, cells could be assembled in the SE, as recent evidence indicates may be the case for CMV (Blackman et al. 1998). At the present time, there are no data in support of either of these hypotheses.

\section{MATERIALS AND METHODS}

Virus, plants, and inoculations.

Cucumber green mottle mosaic tobamovirus, strain $\mathrm{SH}$ (CGMMV-SH) (Ugaki et al. 1991) was the gift of M. Nishiguchi, Kyushu National Agricultural Station, Japan. CGMMV was multiplied in cucumber plants (Cucumis sativus $\mathrm{L}$. 'Ashley'), and virus particles were purified according to Fu-
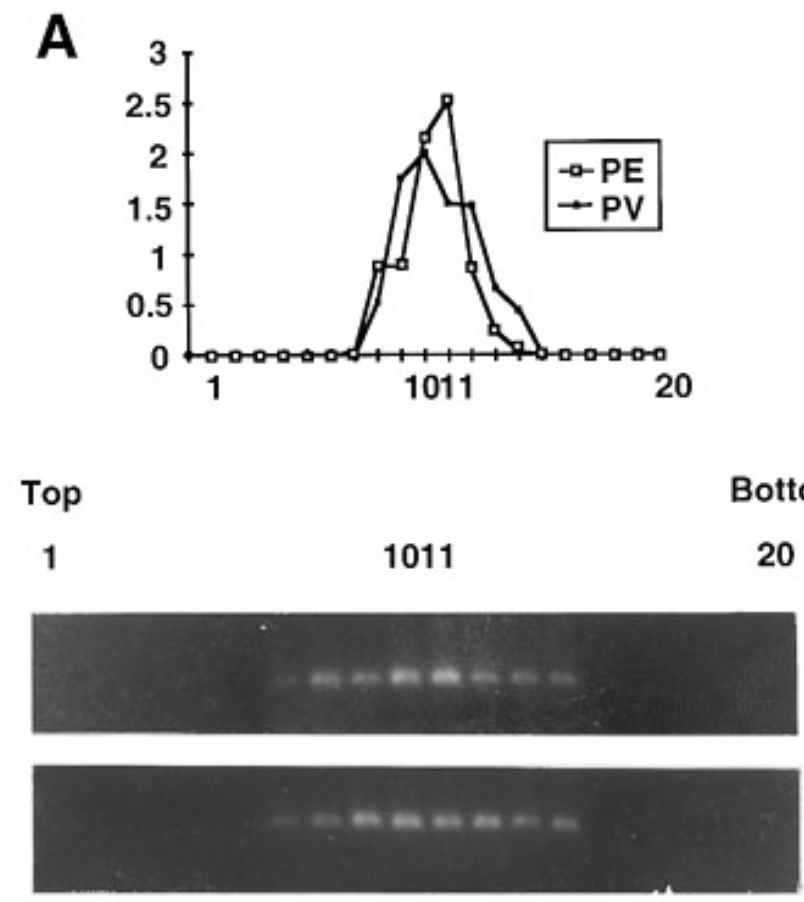

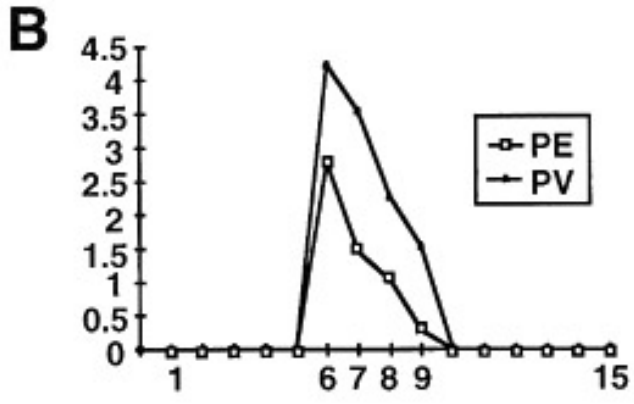

Top

Bottom

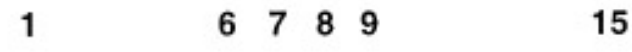

PE

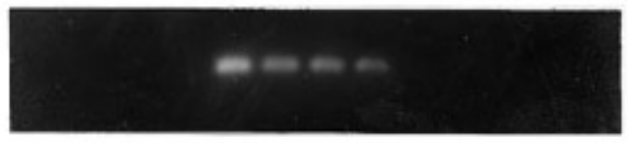

PV

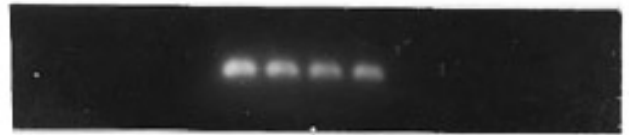

Fig. 5. Analysis of the mass and isopycnic density of the viral structures present in the phloem exudate of cucumber green mottle mosaic tobamovirus (CGMMV)-inoculated cucumber plants. A, RT-PCR (reverse transcription-polymerase chain reaction) detection (nucleotides 4321 to 4680 ) in 20 fractions $(0.5 \mathrm{ml})$ of a 10 to $30 \%$ sucrose gradient loaded with either purified virions mixed with phloem exudate of noninoculated cucumber plants (PV), or phloem exudate of CGMMV-infected cucumber plants (PE). Fractions were collected from the top (1) to the bottom (20) of the gradient. A densitometric profile of the RT-PCR-amplified DNA bands in the agarose gels is shown in the graph above. B, RT-PCR detection (nucleotides 4321 to 4680 ) in 15 fractions $(0.5 \mathrm{ml})$ of a discontinuous $\mathrm{CsCl}$ gradient loaded with either purified virions mixed with phloem exudate of noninoculated cucumber plants (PV), or phloem exudate of CGMMV-infected cucumber plants (PE). Fractions were collected from the top (1) to the bottom (15) of the gradient. A densitometric profile of the RT-PCR-amplified DNA bands in the agarose gels is shown in the graph above. A and B, The numbers on the $y$ axis in the graphs are in arbitrary units. 
kuda et al. (1981). Plants were inoculated with a suspension of virus particles, $300 \mu \mathrm{g} / \mathrm{ml}$ in $10 \mathrm{mM}$ sodium phosphate buffer, $\mathrm{pH} 7.0$, by applying $5 \mu \mathrm{l}$ to the adaxial surface of fully expanded cotyledons of plants in which the first true leaf was expanding (approximately 10 days after sowing). Healthy or inoculated plants were kept in a growth chamber at $24^{\circ} \mathrm{C}$ and a $14 \mathrm{~h}$ light / $10 \mathrm{~h}$ dark cycle. For local lesion assays fully expanded half leaves of Chenopodium amaranticolor Coste \& Reyn. plants were inoculated.

\section{Collection of samples.}

Samples from inoculated plants, or from mock-inoculated controls, were taken at different times post inoculation according to the experiment. Phloem exudate samples were collected from the acropetal side of a sectioned internode. The sectioned internode was always the one below the youngest expanding leaf, which was 1.5 to $2 \mathrm{~cm}$ in length at its major vein. To minimize contamination with sap of parenchyma cells, the first drop of exudate was wiped off with tissue paper and discarded. Subsequent drops of exudate were immediately diluted in four volumes of phloem exudation buffer (PEB) (Read and Northcote 1983). Samples from leaves and/or from internode tissues were also collected, and extracts were made by grinding them in PEB to a final concentration of $0.5 \mathrm{~g}$ per $\mathrm{ml}$, for leaves, or $1.0 \mathrm{~g}$ per $\mathrm{ml}$, for internodes. The extracts were centrifuged for $2 \mathrm{~min}$ in an Eppendorf centrifuge, and the supernatants were collected.

\section{Protein analyses.}

The total amount of proteins in phloem exudate, or in leaf or internode extracts, was quantified as described by Bradford (1976). Proteins were analyzed by electrophoresis in 15\% sodium dodecyl sulfate-polyacrylamide gels, and either stained with Coomassie Brilliant Blue, or transferred to nitrocellulose

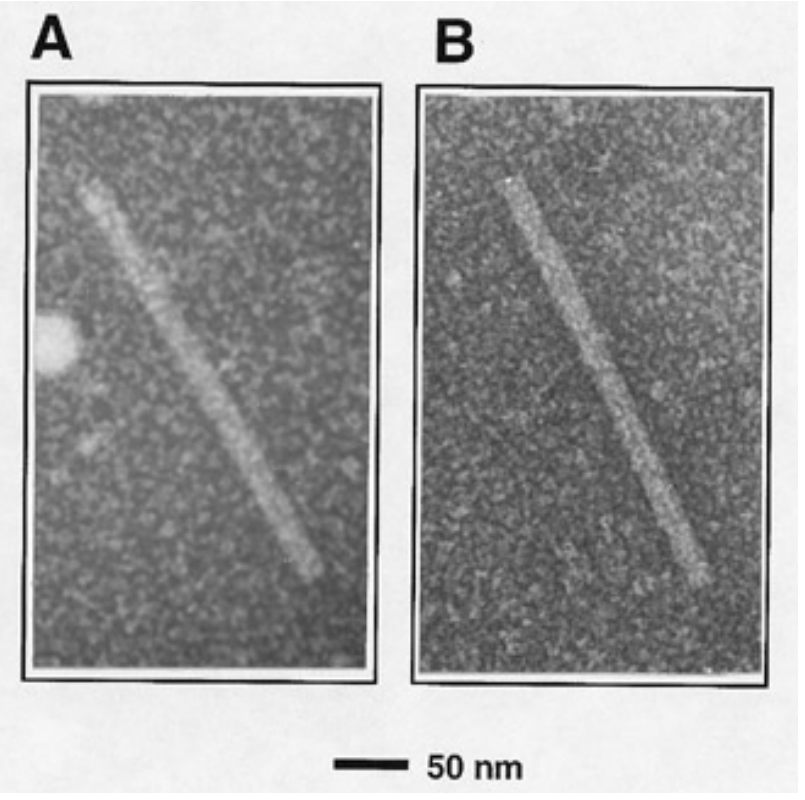

Fig. 6. Electron microscopy of virus particles in fraction 10 of sucrose gradients in which (A) purified cucumber green mottle mosaic tobamovirus (CGMMV) virions mixed with phloem exudate of noninoculated cucumber plants, or (B) phloem exudate of CGMMV-infected cucumber plants, had been centrifuged. for immunoblots. Immunoblots were done as described by Moreno et al. (1997) with antisera against wheat ribulose-1,5bisphosphate carboxylase-oxygenase (rubisco), the gift of $\mathrm{C}$. Schobert (Plant Biology Department, University of California at Davis), or against purified particles of CGMMV, raised by us in New Zealand white rabbits.

\section{Nucleic acid analyses.}

CGMMV RNA in phloem exudate or in tissue extracts was detected by RT-PCR, with the following pairs of primers: LS1-LS2, LS3-LS4, LS5-LS6. LS1 (5'-GTTTCGCCTCAAA ATTCC-3') was complementary to nucleotides 4663 to 4680 of CGMMV RNA; LS2 (5'-TCAAAATATGACAAGTCGC$\left.3^{\prime}\right)$ was identical to nucleotides 4321 to 4339; LS3 (5'AGTGAGCTGATCAACCG-3') was complementary to nucleotides 1365 to 1381; LS4 (5'-ATTGCTTTTAGGTTCGCC$\left.3^{\prime}\right)$ was identical to nucleotides 765 to 782 ; LS5 (5'TCGACCCTAAACTGAGCCCC-3') was complementary to nucleotides 805 to 824 ; LS6 (5'-ATCATCAAGACAGACGC CCG-3') was identical to nucleotides 179 to 198 . Primer LS7 was complementary to the $3^{\prime}$ end of CGMMV RNA (5'-TGG GCCCCTACCCGGGG-3') (nucleotides 6405 to 6421).

For RT-PCR, $5 \mu \mathrm{l}$ of phloem exudate, diluted in $20 \mu \mathrm{l}$ of PEB, was further diluted with $25 \mu \mathrm{l}$ of PEB, phenol extracted, ethanol precipitated, and resuspended in $50 \mu \mathrm{l}$ of water. Three microliters of the resuspension was mixed with $4 \mu$ of $\mathrm{M}$ MLV Reverse Transcriptase buffer $5 \times(250 \mathrm{mM}$ Tris $\cdot \mathrm{HCl}, \mathrm{pH}$ $8.3,375 \mathrm{mM} \mathrm{KCl}, 15 \mathrm{mM} \mathrm{MgCl}_{2}, 50 \mathrm{mM}$ DTT [dithiothreitol]), $1 \mu \mathrm{l}$ of dNTPs mix, $10 \mathrm{mM}$ each, $2 \mu \mathrm{l}$ of $10 \mathrm{mM}$ DTT, 25 pmol of oligonucleotides LS1, LS3, LS5, or LS7, 50 units of M-MLV Reverse Transcriptase, and water to $20 \mu \mathrm{l}$. This mixture was incubated at $37^{\circ} \mathrm{C}$ for $1 \mathrm{~h}$ and $95^{\circ} \mathrm{C}$ for 5 min. The newly synthesized cDNA $(2.5 \mu \mathrm{l})$ was subjected to PCR by mixing it with $2.5 \mu \mathrm{l}$ of $10 \times$ PCR buffer $(100 \mathrm{mM}$ Tris. $\mathrm{HCl}, \mathrm{pH} 8.8,15 \mathrm{mM} \mathrm{MgCl} 2,500 \mathrm{mM} \mathrm{KCl}, 1 \%$ Triton X100), $0.5 \mu \mathrm{l}$ of dNTPs mix, $10 \mathrm{mM}$ each, $25 \mathrm{pmol}$ of oligonucleotides LS1, LS3, LS5, or LS7, 25 pmol of oligonucleotides LS2, LS4, or LS6, 1 U of Taq DNA polymerase, and water to 25 $\mu \mathrm{l}$. The conditions of the PCR were 35 cycles of $95^{\circ} \mathrm{C} 30 \mathrm{~s}$, $52^{\circ} \mathrm{C}\left(5^{\circ} \mathrm{C}\right.$ below the $T_{\mathrm{m}}$ for both oligonucleotides) $30 \mathrm{~s}, 72^{\circ} \mathrm{C} 1$ min; $125 \mathrm{ng}$ of purified CGMMV virion particles (equivalent to 7.5 ng of RNA) in $25 \mu \mathrm{l}$ of PEB was used as a positive control. RT-PCR products were analyzed in $1 \%$ agarose electrophoresis gels and viewed after staining with ethidium bromide.

\section{Resistance to RNase A digestion.}

Five microliters of phloem exudate diluted in $20 \mu \mathrm{l}$ of PEB was digested with increasing concentrations of RNase A, from $5 \times 10^{-6} \mathrm{mg} / \mathrm{ml}$ to $25 \mathrm{mg} / \mathrm{ml}$, final concentration, and subjected to the RT-PCR protocol described above. Purified CGMMV virus particles (125 ng) in $25 \mu \mathrm{l}$ of PEB were used as controls. Several experiments were done to characterize the resistance to RNase digestion, as detailed in the Results.

\section{Rate zonal and isopycnic centrifugation.}

Rate zonal centrifugation was in 10 to $30 \%$ sucrose gradients loaded with $30 \mu \mathrm{g}$ of purified virus particles, alone or mixed with $70 \mu \mathrm{l}$ of phloem exudate from noninoculated cucumber plants and $280 \mu \mathrm{l}$ of $\mathrm{PEB}$, or with $70 \mu \mathrm{l}$ of phloem exudate from CGMMV-inoculated cucumber plants diluted in $280 \mu \mathrm{l}$ of PEB. Centrifugation was for $1 \mathrm{~h} 45 \mathrm{~min}$ at 30,000 rpm in an SW40 
rotor (Beckman, Palo Alto, CA). For isopycnic centrifugation, the same amounts of purified virions, alone or mixed with $70 \mu \mathrm{l}$ of phloem exudate of noninoculated cucumber plants, or of phloem exudate from CGMMV-infected plants, were taken to $0.2 \mathrm{mg}$ of $\mathrm{CsCl}$ per $\mathrm{ml}$ and loaded in a discontinuous $\mathrm{CsCl}$ gradient (from bottom to top: $1.25 \mathrm{ml}$ of $\mathrm{CsCl} 53 \%, 1.25 \mathrm{ml}$ of $\mathrm{CsCl} 45 \%, 1.25 \mathrm{ml}$ of $\mathrm{CsCl} 39 \%$ ). Centrifugation was for $20 \mathrm{~h}$ at 40,000 rpm in an SW41 rotor (Beckman). Fractions (0.5 ml) were collected by hand. Five microliters from each fraction was mixed with $45 \mu \mathrm{l}$ of water, phenol extracted, and subjected to RT-PCR as described above. Microdialysis against water was carried out with the $\mathrm{CsCl}$ fractions prior to phenol extraction to eliminate the Cs ions that would inhibit the RTPCR. For dialysis, a nitrocellulose filter with a pore diameter of $0.025 \mu \mathrm{m}$ was floated over water and $20 \mu \mathrm{l}$ of each fraction was placed on the filter for $15 \mathrm{~min}$.

\section{Electron microscopy.}

Ten-microliter samples from the sucrose gradients fractions were placed on electron microscope grids coated with antisera against the CGMMV particles. After the grids were washed

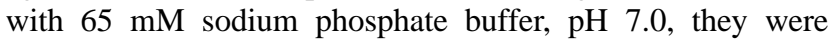
treated for 2 min with $2 \%$ phosphotungstic acid and viewed under an electron microscope (model JEM-1200 EXII; Jeol, Tokyo) at a magnification of $\times 150,000$.

\section{ACKNOWLEDGMENTS}

We want to thank M. Nishiguchi, Kyushu National Agricultural Station, Japan, for the gift of CGMMV-SH strain; C. Schobert, Plant Biology Department, University of California-Davis, for antisera against rubisco; and E. Rodríguez-Cerezo, Centro Nacional de Biotecnología, Madrid, Spain, for access to electron microscope facilities. This work was in part supported by grants BIO 96-1026-002-01 and PTR 95-0019OP, CICYT, Spain.

\section{LITERATURE CITED}

Allison, R. F., Thompson, C., and Ahlquist, P. 1990. Regeneration of a functional RNA virus genome by recombination between deletion mutants and requirement for cowpea chlorotic mottle virus $3 \mathrm{a}$ and coat protein genes for systemic infection. Proc. Natl. Acad. Sci. USA 87:1820-1824.

Altschuh, D., Lesk, A. M., Bloomer, A. C., and Klug, A. 1987. Correlation of co-ordinated amino acid substitutions with function in viruses related to tobacco mosaic virus. J. Mol. Biol. 193:693-707.

Blackman, L. M., Boevink, P., Santa Cruz, S., Palukaitis, P., and Oparka, K. J. 1998. The movement protein of cucumber mosaic virus traffics into sieve elements in minor veins of Nicotiana clevelandii. Plant Cell 10:525-537.

Bradford, M. M. 1976. A rapid and sensitive method for the quantitation of microgram quantities of protein utilizing the principles of proteindye binding. Anal. Biochem. 72:248-254.

Caldwell, J. 1934. The physiology of virus diseases in plants. V. The movement of the virus agent in tobacco and tomato. Ann. Appl. Biol. 21:191-205.

Carrington, J. C., Kasschau, K. D., Mahajan, S. K., and Schaad, M. C. 1996. Cell-to-cell and long-distance transport of viruses in plants. Plant Cell 8:1669-1681.

Dawson, W. O., Bubrick, P., and Grantham, G. L. 1988. Modification of the tobacco mosaic virus coat protein gene affecting replication, movement, and symptomatology. Phytopathology 78:783-789.

Ding, X. S., Shintaku, M. H., Carter, S. A., and Nelson, R. S. 1996. Invasion of minor veins of tobacco leaves inoculated with tobacco mosaic virus mutants defective in phloem-dependent movement. Proc. Natl. Acad. Sci. USA 93:11155-11160.

Dolja, V. V., Haldelman-Cahill, R., Montgomery, A. E., Vandenbosch, K. A., and Carrington, J. C. 1994. Capsid protein determinants in- volved in cell-to-cell and long distance movement of tobacco etch potyvirus. Virology 206:1007-1016.

Dorokhov, Y. L., Alexandrova, N. M., Miroshnichenko, N. A., and Atabekov, J. G. 1983. Isolation and analysis of virus-specific ribonucleoprotein of tobacco mosaic virus-infected tobacco. Virology 127:237-252.

Dorokhov, Y. L., Alexandrova, N. M., Miroshnichenko, N. A., and Atabekov, J. G. 1984. The informosome-like virus-specific ribonucleoprotein (vRNP) may be involved in the transport of tobacco mosaic virus infection. Virology 137:127-134.

Esau, K., and Cronshaw, J. 1967. Tubular components in cells of healthy and tobacco mosaic virus-infected Nicotiana. Virology 33:26-35.

Fukuda, M., Meshi, T., Okada, Y., Otsuki, Y., and Takebe, I. 1981. Correlation between particle multiplicity and location on virion RNA of the assembly initiation site for viruses of the tobacco mosaic virus group. Proc. Natl. Acad. Sci. USA 78:4231-4235.

Gilbertson, R. L., and Lucas, W. J. 1996. How do virus traffic on the "vascular highway"? Trends Plant Sci. 1:260-268.

Hacker, D. L., Petty, I. T. D., Wei, N., and Morris, T. J. 1992. Turnip crinkle virus genes required for RNA replication and virus movement. Virology 186:1-8.

Kempers, R., Prior, D. A. M., van Bel, A. J. E., and Oparka, K. J. 1993. Plasmodesmata between sieve element and companion cell of extrafascicular stem phloem of Cucurbita maxima permit passage of $3 \mathrm{kDa}$ fluorescent probe. Plant J. 4:567-575.

Kempers, R., and van Bel, A. J. E. 1997. Symplasmic connections between sieve element and companion cell in the stem phloem of Vicia faba $\mathrm{L}$. have a molecular exclusion limit of at least $10 \mathrm{kDa}$. Planta 201:195-201.

Leisner, S. M., and Turgeon, R. 1993. Movement of virus and photoassimilate in the phloem: A comparative analysis. Bioessays 15:741-748.

Moreno, I. M., Bernal, J. J., García de Blas, B., Rodríguez-Cerezo, E., and García-Arenal, F. 1997. The expression level of the 3a movement protein determines differences in severity of symptoms between two strains of tomato aspermy cucumovirus. Mol. Plant-Microbe Interact. 10:171-179.

Nelson, R. S., and van Bel, A. J. E. 1998. The mystery of virus trafficking into, through and out of vascular tissue. Prog. Bot. 59:476-533.

Oxelfelt, P. 1975. Development of systemic tobacco mosaic virus infection. IV. Synthesis of viral RNA and intact virus and systemic movement of two strains as influenced by temperature. Phytopathol. Z. 83: 66-76.

Perham, R. N., and Wilson, T. M. A. 1978. The characterization of intermediates formed during the disassembly of tobacco mosaic virus at alkaline pH. Virology 84:293-302.

Read, S. M., and Northcote, D. H. 1983. Chemical and immunological similarities between the phloem proteins of three genera of the Cucurbitaceae. Planta 158:119-127.

Saito, T., Yamanaka, K., and Okada, Y. 1990. Long-distance movement and viral assembly of tobacco mosaic virus mutants. Virology 176: 329-336.

Santa Cruz, S., Roberts, A. G., Prior, D. A. M., Chapman, S., and Oparka, K. J. 1998. Cell-to-cell and phloem-mediated transport of potato virus X: The role of virions. Plant Cell 10:495-510.

Schulz, A. 1998. Phloem. Structure related to function. Prog. Bot. 59: 429-475.

Tomenius, K., Clapham, D., and Meshi, T. 1987. Localization by immunogold cytochemistry of the virus-encoded $30 \mathrm{~K}$ protein in plasmodesmata of leaves infected with tobacco mosaic virus. Virology 160:363-371.

Ugaki, M., Tomiyama, M., Takutani, T., Hidaka, S., Kiguchi, T., Nagata, R., Sato, T., Motoyoshi, F., and Nishiguchi, M. 1991. The complete nucleotide sequence of cucumber green mottle mosaic virus ( $\mathrm{SH}$ strain) genomic RNA. J. Gen. Virol. 72:1487-1495.

Vaewhongs, A. A., and Lommel, S. A. 1995. Virion formation is required for the long-distance movement of red clover necrotic mosaic virus in movement protein transgenic plants. Virology 212:607-613.

Wilson, T. M. A., Lomonossoff, G. P., and Glover, J. F. 1981. Dimethyl sulphoxide (DMSO) disassembles tobacco mosaic virus predominantly from the 5'-end of the viral RNA. J. Gen. Virol. 53:225-234.

Wintermantel, W. M., Banerjee, N., Oliver, J. C., Paolillo, D. J., and Zaitlin, M. 1997. Cucumber mosaic virus is restricted from entering minor veins in transgenic tobacco exhibiting replicase-mediated resistance. Virology 231:248-257.

Wolf, S., Deom, C. M., Beachy, R. N., and Lucas, W. J. 1989. Movement protein of tobacco mosaic virus modifies plasmodesmatal size exclusion limit. Science 246:377-379. 